\title{
SAVANA ALTER DO CHÃO - NAS CHAMAS DA REDE DE CONTROVÉRSIAS E DA ESPECULAÇÃO IMOBILIÁRIA
}

\author{
Talita Cristina Araújo Baena ${ }^{1}$
}

\section{Introdução}

Os conflitos e as perturbações socioambientais na Savana Alter do Chão, localizada no município de Santarém, no Oeste do Pará, não é um fenômeno recente. A especulação imobiliária na área, que também é Área de Proteção Ambiental (APA) - a APA Alter do Chão, já foi denunciada ao Ministério Público do Estado e ao Ministério Público da União em anos anteriores ${ }^{2}$. Porém, o mais recente episódio, os incêndios de Alter do Chão, em setembro de 2019, chamou a atenção da mídia nacional e internacional e reaqueceu a controvérsia, uma vez que o acontecimento do incêndio trouxe à tona o problema da especulação imobiliária como impacto ambiental, em áreas de proteção ambiental. Além disso, alguns estudos de clima e meio ambiente produziram dispositivos de verdade cientifica - os artigos desenhando o cenário da savanização ${ }^{3}$ da floresta amazônica, a partir da problemática do aumento do fogo e do desmatamento em todo o bioma Amazônia.

De acordo com uma das inúmeras reportagens produzidas pelo G1 Santarém e Região sobre o assunto, a grilagem na APA Alter do Chão teria sido feita por Silas Soares (Fig.1), acusado de desmatamento ilegal dentro de uma área que populares e as reportagens da época denominavam de Capadócia. E foi justamente no loteamento "na Capadócia" onde os focos do incêndio, que ocorreram entre os dias 14 e 17 de setembro de 2019, concentraram-se.

\footnotetext{
1 Universidade Federal do Oeste do Pará (Ufopa). Email: talita.baena@gmail.com. ORCID: https://orcid.org/0000-0002-0018-903X

2 Como mostra a notícia do G1Santarém e Região, publicada no dia 19/09/2019: https://g1.globo.com/pa/santarem-regiao/noticia/2019/09/19/mpf-suspeita-que-incendio-em-alter-do-chao-tenhainiciado-em-area-invadida-por-grileiro-condenado-em-2018.ghtml

${ }^{3} \mathrm{O}$ artigo de Scoot Stark e colaboradores, que são pesquisadores da rede do grupo de pesquisa Brama-Ufopa, está disponível aqui: https://esajournals.onlinelibrary.wiley.com/doi/full/10.1002/ecs2.3231
} 
Figura 1 - Reportagem sobre grilagem e especulação na área do incêndio em Alter do Chão

$\leftarrow$ G1 Santarém e Região

\title{
MPF suspeita que incêndio em Alter do Chão tenha começado em área invadida por grileiro condenado em 2018
}

\author{
Silas da Silva Soares está foragido, mas \\ advogado nega envolvimento dele em \\ incêndios. Ele foi condenado a seis \\ anos e dez meses de prisão por instalar \\ loteamento dentro da APA Alter do \\ Chão. \\ Por G1 Santarém \\ 19/09/2019 06hoo • Atualizado há 23 meses
}

Para este ensaio fotográfico, que faz uso dos registros fotográficos e audiovisuais do diário de campo e das controvérsias mapeadas na minha pesquisa de doutorado, Amazônia Informacional: Comunicação e Controvérsias Políticas na Tecnociência do Clima e Meio Ambiente $^{4}$, relembro aqui, como foram aqueles dias quando os celulares e os sites de redes sociais daqueles que habitam a cidade de Santarém, Oeste do Pará, foram inundados de fotos e vídeos assustadores dos brigadistas e banhistas, estes últimos, que estavam na Praia do Amor naquele final de semana.

\footnotetext{
${ }^{4} \mathrm{O}$ projeto Amazônia informacional: comunicação na rede da tecnociência do clima e meio ambiente foi autorizado pelo Comitê de Ética em Pesquisa (CEP), UEPA-Santarém, (PROTOCOLO CAAE 44934821.1.0000.5168).
} 
A vivência da pesquisa-intervenção para a elaboração de uma cartografia movente, a partir da observação participante tendo como principal aliado a fotografia e filme documental, no grupo de pesquisa Brama - Ufopa, Grupo de Pesquisa em Biogeofísica da Região Amazônica e Modelagem Ambiental, sediado no Laboratório de Física e Química da Atmosfera da Universidade Federal do Oeste do Pará (Ufopa), possibilitou ações de comunicação pública de ciência e também o registro da memória dos efeitos dos incêndios não só na área, mas também nos instrumentos da estação micrometeorológica, instalada na comunidade de Ponta de Pedras, também afetada pelo incêndio.

Além disso, acompanhar os processos de produção de verdades científicas em um grupo de pesquisa ambiental na e da Amazônia, ofereceu novas pistas, atores e associações em torno do incêndio na Savana Alter do Chão, a exemplo do artigo "Reframing tropical savannization: linking changes in canopystructure to energy balance alterations that impact climate", na Ecosphere, seção Innovative Viewpoints”, que, um ano após o incêndio, anunciava a savanização da Amazônia como um dos possíveis efeitos coletivos das perturbações como queimadas e desmatamento, na Floresta Amazônica.

\section{Domingo, 15 de setembro de 2019, horas depois do início do incêndio}

As informações que chegavam nos grupos de WhatsApp e de portais de notícias, naquela manhã de domingo, eram de que um grande incêndio havia atingido Alter do Chão e Ponta de Pedras, em Santarém. O fogo, de acordo com os brigadistas, iniciou na noite anterior, no sábado, dia 14 de setembro de 2019.

Em reportagem, Daniel Gutierrez Govino ${ }^{5}$, um dos brigadistas que trabalhou para controlar a propagação do fogo na floresta da Savana Alter do Chão, relatou na época que havia três grandes focos de incêndio. Um menor foi controlado; o segundo foco, o vento e o posicionamento da estrada iriam favorecer para que o mesmo fosse apagado sozinho. Assim ele conta na reportagem: "Por estratégia, vamos atacar o maior. Esse fogo está desde Alter do Chão até Ponta de Pedras. Estamos chamando voluntários e apoio de lanchas para tentar apagar o fogo que está muito alto", explicou Daniel Govino, na primeira das dezenas de entrevistas e reportagens, que foram realizadas sobre o controle do fogo, as causas e os culpados pelo crime ambiental.

\footnotetext{
${ }^{5}$ Produtor Cultural, fotógrafo e morador de Alter do Chão; Cofundador da Brigada de Alter.
} 
Naquela manhã de domingo, centenas de fotos eram compartilhadas pelas redes sociais, mas o vídeo produzido pelos brigadistas, que foi publicado no Twitter do perfil Mídia Ninja, foi o que fez o mundo voltar as atenções para Alter do Chão, com mais 20 mil visualizações (Fig. 2).

Figura 2 - Captura de tela do tweet do perfil Mídia Ninja

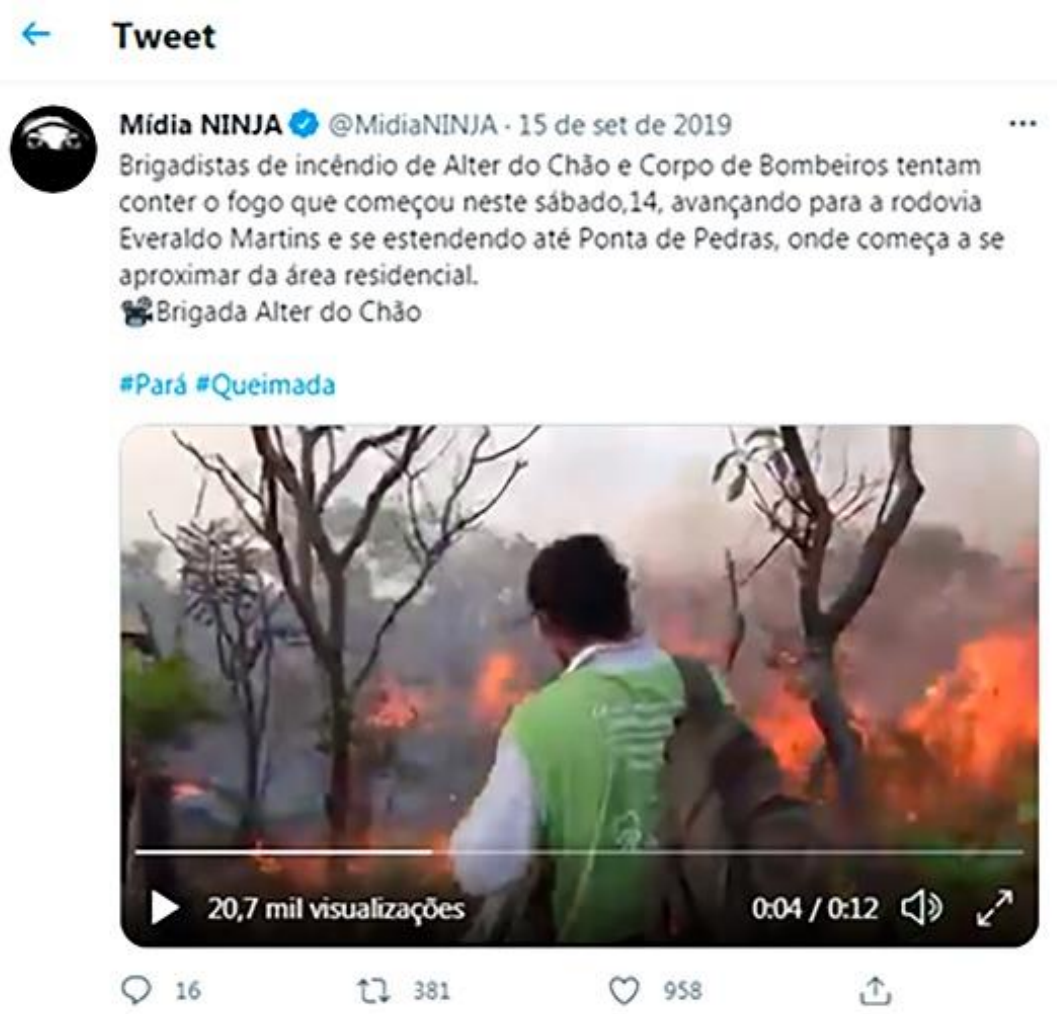

Apesar do amplo interesse nas plataformas de redes sociais complexas, a cobertura jornalística local sobre o incêndio se ateve ao trabalho de combate dos brigadistas, do Corpo de Bombeiros e também das investigações da Polícia Civil. O fato de a área ser um ecossistema específico dentro do Bioma Amazônia, com parcelas de pesquisas do Programa de Pesquisa em Biodiversidade do Instituto Nacional de Pesquisas na Amazônia (INPA), não foi enfatizado nos noticiários, o que contribui negativamente para a percepção ambiental e da preservação da fauna e da flora dos ecossistemas amazônicos, transformando a estrutura de sentimento do que é área de proteção ambiental e que precisa ser preservada para uma outra ideia de área que pode ser loteada e que, portanto, seria comum queimar e desmatar para "limpar a área".

E foi toda essa controvérsia reaquecida sobre queimadas na Amazônia que atravessou o trabalho de cortar a rede sociotécnica de um laboratório. Esses cortes e atravessamentos das 
redes do acontecimento incêndio, o olhar fotográfico e audiovisual da observação participante revelaram como natureza e sociedade são inseparáveis. Pois ambas, natureza e sociedade são um emaranhado de híbridos humanos, não-humanos e objetos técnicos, com os seus respectivos agenciamentos. Como enfatiza Bruno Latour sobre a separação, que fazem os modernos, dos humanos e não-humanos: "Tudo acontece no meio, tudo transita entre as duas, tudo ocorre na mediação, por tradução e por redes”, (LATOUR, 1994, p. 43).

\begin{abstract}
Diário de Campo
Sexta-feira, Dia 20 de setembro de 2019

Ao longo da semana, o incêndio e suas controvérsias tomaram conta dos noticiários. $\mathrm{O}$ combate ao fogo continuou até o dia 17. Os pesquisadores do laboratório que trabalhavam com a estação micrometereológica da comunidade Ponta de Pedras, principalmente os Prof. Júlio Tota ${ }^{6}$, o Prof. Rodrigo da Silva ${ }^{7}$ e o Prof. Marcos Delfino ${ }^{8}$ acompanharam a situação entrando em contato com comunitários para saber se o fogo estava chegando próximo a torre.

Em paralelo, mantive o contato com o professor Rodrigo Fadini ${ }^{9}$, que realiza pesquisas ecológicas em áreas de savana. Como ele mantinha diálogo com a minha pesquisa, expliquei a ele meu interesse de visitar o local e verificar o nível da degradação ambiental e os impactos nas pesquisas, tanto as de clima quanto as de meio ambiente. Neste último caso, especificamente, refiro-me àquelas desenvolvidas pelo $\mathrm{PPBio}^{10}$, que possui um grupo de pesquisadores ambientais bastante atuante nas questões relacionadas à APA Alter do Chão.

Por causa das agendas dos pesquisadores e dos meus compromissos com a disciplina de Antropologia da Natureza, que eu fazia como ouvinte no curso de Antropologia da Ufopa, com o professor Miguel Aparicio Suarez ${ }^{11}$, só foi possível ir a campo, quase uma semana depois, na sexta-feira, dia 20.

Avner Gaspar' ${ }^{12}$, o outro doutorando do grupo de pesquisa e orientando do professor Rodrigo, conseguiu agendar o carro para a visita, então fomos eu, ele, a também doutoranda, Gabriela Godinho ${ }^{13}$ e os professores Rodrigo da Silva e Marcos Delfino. Ao logo do caminho rumo à área do incêndio, houve comentários sobre o histórico de especulação imobiliária na área, inclusive, com denúncias no Ministério Público do Estado $^{14}$.
\end{abstract}

\footnotetext{
${ }^{6}$ Meteorologista e docente do PPGSND-Ufopa e professor adjunto do curso de graduação em Ciências Atmosféricas (CA), do Instituto de Engenharia e Geociências (IEG) da Universidade Federal do Oeste do Pará (UFOPA).

${ }^{7}$ Licenciado, mestre e doutor em Física pela UFSM. Docente do curso de graduação em Ciências Atmosféricas (CA) e do PPGSND da Ufopa, orientador/interlocutor desta minha pesquisa de doutorado em ciências ambientais.

${ }^{8}$ Meteorologista e professor do curso de graduação em Ciências Atmosféricas (CA), do Instituto de Engenharia e Geociências (IEG) da Universidade Federal do Oeste do Pará (UFOPA).

9 Biólogo, com doutorado em ecologia, que pesquisa as interações entre animais consumidores de frutos e plantas; Ecologia de plantas parasitas; Ecologia de savana na Savana Alter do Chão, em parceria com a rede de pesquisadores do Programa de Pesquisa em Biodiversidade (INPA).

${ }^{10}$ Programa de Pesquisa em Biodiversidade. Site do programa: https://ppbio.inpa.gov.br/.

11 Coordenador do Programa de Pós-graduação em Ciências da Sociedade e professor no Programa de Antropologia e Arqueologia.

12 Agrônomo, técnico da Fazenda Experimental da Ufopa, membro do grupo Brama-Ufopa, doutorando no PPGSND da mesma universidade, orientando do professor Rodrigo da Silva.

13 Engenheira física, bolsista de pós-graduação, doutoranda no PPGSND, também é orientanda do professor Rodrigo da Silva.

${ }^{14}$ Notícia do site do Ministério Público do Estado do Pará sobre o incêndio de 2019, com histórico de crimes ambientais ocorridos na área: https://www2.mppa.mp.br/noticias/processo-de-incendio-em-alter-do-chao-emantido-na-esfera-estadual.htm
} 
Como jornalista e pesquisadora, eu estava diante de um relato e denúncia, que também era uma controvérsia envolvendo a esfera judicial e portanto, provavelmente, corria em segredo de justiça. $\mathrm{O}$ aspecto da ética na pesquisa veio à tona. Não por uma imposição legal e orientação do colegiado do programa de pós-graduação ou da prerrogativa do direito de participar ou não da pesquisa. A ética jornalística e da pesquisa apareciam ali como um dilema: "é preciso mostrar a ciência em ação com base na realidade dos fatos, mas qual é o momento mais adequado? Devo acrescentar esta fala nos textos de comunicação de ciência das redes sociais do grupo de pesquisa? Eu ouvi o relato atentamente, porém eu também tinha outras preocupações e decisões técnicas para tomar até a chegada ao local: devo filmar ou fotografar? A temperatura da luz já está muito alta, eu não podia errar na composição fotográfica, na abertura do diafragma e na velocidade do obturador, pois os rastros e vestígios do incêndios já estavam se perdendo com a transição e passagem do tempo e o tempo daquele desastre ambiental não voltaria".

Levando em conta todas essas questões, eu decidi por priorizar a filmagem devido a possibilidade de capturar o frame de vídeo, caso eu quisesse utilizar uma imagem em movimento como fotografia. Não é o ideal, mas são escolhas necessárias quando as condições do campo são extremamente dinâmicas e não há muito tempo para uma fotografia mais contemplativa. As coisas no campo acontecem muito rápido, ainda mais diante de um sol no verão amazônico de quase meio dia, em meio a savana. Então, percebi que o que importava ali era o registro fotográfico mais apropriado para as condições de produção. Então eu decidi: “irei filmar o caminhar até a chegada à torre". Certamente, esta decisão estava sob a influência das leituras de Comolli durante a cadeira (disciplina) de montagem e mise en scene, que eu fiz no doutorado de comunicação na UFPE, dois meses antes do incêndio.

O primeiro ponto visitado foi a estação de microclima, instalada em 2017, mas que só começou a fazer as medições das variáveis climáticas, em 2018. Por causa da série temporal, era grande a preocupação com os dados, pois semanas antes havia ocorrido um problema e os dados não foram coletados. Logo que chegamos, como de costume nessas atividades em campo, o professor Rodrigo foi descrevendo o que estava fazendo, comentado sobre cada instrumento da estação: computador Raspberry Pi do sistema; o datalog, os três sensores e o que cada um estava medindo e com que frequência de Hertz.

Como um dos focos do incêndio ocorreu cerca de 700 metros ao norte do local onde a estação está instalada, depois da coleta dos dados, seguimos na estrada em direção à área do incêndio para que o Avner pudesse coletar amostras de solo para caracterizar o perfil do solo da Savana afetada pelo fogo. Enquanto ele fazia as coletas, eu fazia as filmagens e algumas fotos num celular. O professor Rodrigo subiu o drone. A visão era desoladora, aquele conjunto de árvores carbonizadas parecia uma cena de um filme apocalíptico de guerra e a minha preocupação era se eu conseguiria transmitir toda aquela destruição e desalento em imagens. Por sorte, as imagens de drone do professor Rodrigo mostram o tamanho daquela área afetada pelo fogo, mas ainda havia outros focos do outro lado da pista.

Pelo horário, quase meio dia e as atividades ali cumpridas, voltamos à Santarém. Pensei comigo: "agora é conseguir os relatos dos brigadistas e do professor Fadini".

\section{Diário de Campo \\ Segunda-feira. Dia 27 de setembro de 2019}

Com a mediação do Professor Fadini, consegui um segundo dia de gravações com a participação dos brigadistas de Alter do Chão e da professora da Ufopa, especialista em manejo de Fogo, a Daniela Paulleto. Eu, Fadini e Daniela nos encontramos na Ufopa, Daniel Govino e João Victor Pereira Romano ${ }^{15}$, fundadores da Brigada de Alter do Chão, nos encontramos na estrada Everaldo Martins, antes de pegar a estrada para Ponta de Pedras.

Daniel e João Victor foram generosos porque nos conduziram a uma área onde se percebia bem a transição entre a savana queimada e floresta secundária preservada. Mais uma vez,

15 João Victor é coordenador, fundador e idealizador da Brigada de Alter do Chão e gentilmente aceitou em colaborar com os registros audiovisuais dos efeitos do incêndio de 2019, em Alter do Chão, inclusive, cedendo imagens de drone. 
fiquei bastante assustada com a dimensão daquela outra área, que também foi queimada pelo fogo.

Daniel Govino foi o primeiro a ser entrevistado. E num misto de sensações que variava entre a desconfiança jornalística e o nervosismo de uma entrevista de um assunto tão complexo e perigoso, por não ser apenas um desastre ambiental, mas um incêndio com fortes indícios de ser criminoso, iniciei com uma pergunta sobre as pessoas que se envolveram no combate ao fogo, porém, o que eu mais queria saber era a dimensão do desastre ambiental. Então, perguntei:

_ As pessoas querem ajudar, mas é preciso saber manejar o fogo, não é mesmo, Daniel?

_ Na Brigada, a gente tem 25 pessoas, não todo mundo de Alter do Chão, tem algumas pessoas que estão na Resex, tem algumas pessoas que estão na comunidade aqui e em Santarém também. Na Brigada, nós estávamos girando em torno de 16 pessoas aqui, mas para o combate, tinham mais de 200 porque estava o Exército, estava a Desefa Civil, o $4^{\circ}$ GBM em peso, a Secretaria de Meio Ambiente. Só do Exército eram 150 homens, então, estavam bastante preparados para combater este incêndio. Foi uma operação grande, que deu resultado. Apesar da grande área queimada, se não fosse esse tamanho de operação, o incêndio estava muito sério e poderia ter queimado muito mais.

_ Vocês já sabem a dimensão da área queimada?

_ É entre 1.100 a 1600 ha de área queimada aqui neste incêndio que durou quatro dias.

Depois do Daniel, entrevistei a professora Daniela e o brigadista João Victor ${ }^{16}$. Ela explicava, ao longo da viagem, que é comum a ocorrência de fogo em savanas, porém ela dizia que era preciso saber manejá-lo. Então, já na savana, perguntei a ela como deve ser feito esse manejo:

- O manejo integrado do fogo, ele coloca a possibilidade de você usar o fogo como seu aliado. Nesse caso aqui, nesse incêndio que ocorreu agora, tivemos uma ocorrência não planejada do uso do fogo e isso gerou todo um transtorno, uma necessidade de combate e controle desse fogo. Mas o que a gente traz é que o fogo, historicamente, ele tem sido utilizado como fator de produção, mas é necessário tomar todas as medidas para que o fogo não saia do controle.

Depois dessa fala, a professora Daniela explicou que foi o aceiro, técnica de combate e controle de incêndio, a medida utilizada para combater o fogo na savana Alter do Chão. Ela contou ainda que, como prevenção, o modo de aceiro mais conhecido é a retirada de todo o material combustível, a biomassa, ou seja, toda a serapilheira ou liteira, que é aquela camada de material orgânico em decomposição, presente na superfície do solo de florestas, composta de folhas e galhos secos, além de flores, frutos e sementes caídos de árvores.

Infelizmente, naquela manhã de segunda-feira, uma chuva com tempestade de raio não permitiu a realização da entrevista com o Prof. Rodrigo Fadini, o ecólogo especialista em savanas amazônicas.

$\mathrm{Na}$ volta para Santarém, em meio ao cenário de desastre ambiental, a flora da savana começava a dar sinais de que a vida ressurge após o fogo.

\footnotetext{
${ }^{16}$ João Victor relatou o momento de quando foi comunicado da ocorrência do incêndio via WhatsApp, com imagens da fumaça preta, que na experiência de brigadista se trata de um fogo grande.
} 


\section{O ensaio}

Savana Alter do Chão - Nas Chamas da controvérsia e da degradação

Imagem 1 - A cena dos vestígios do fogo depois da estrada

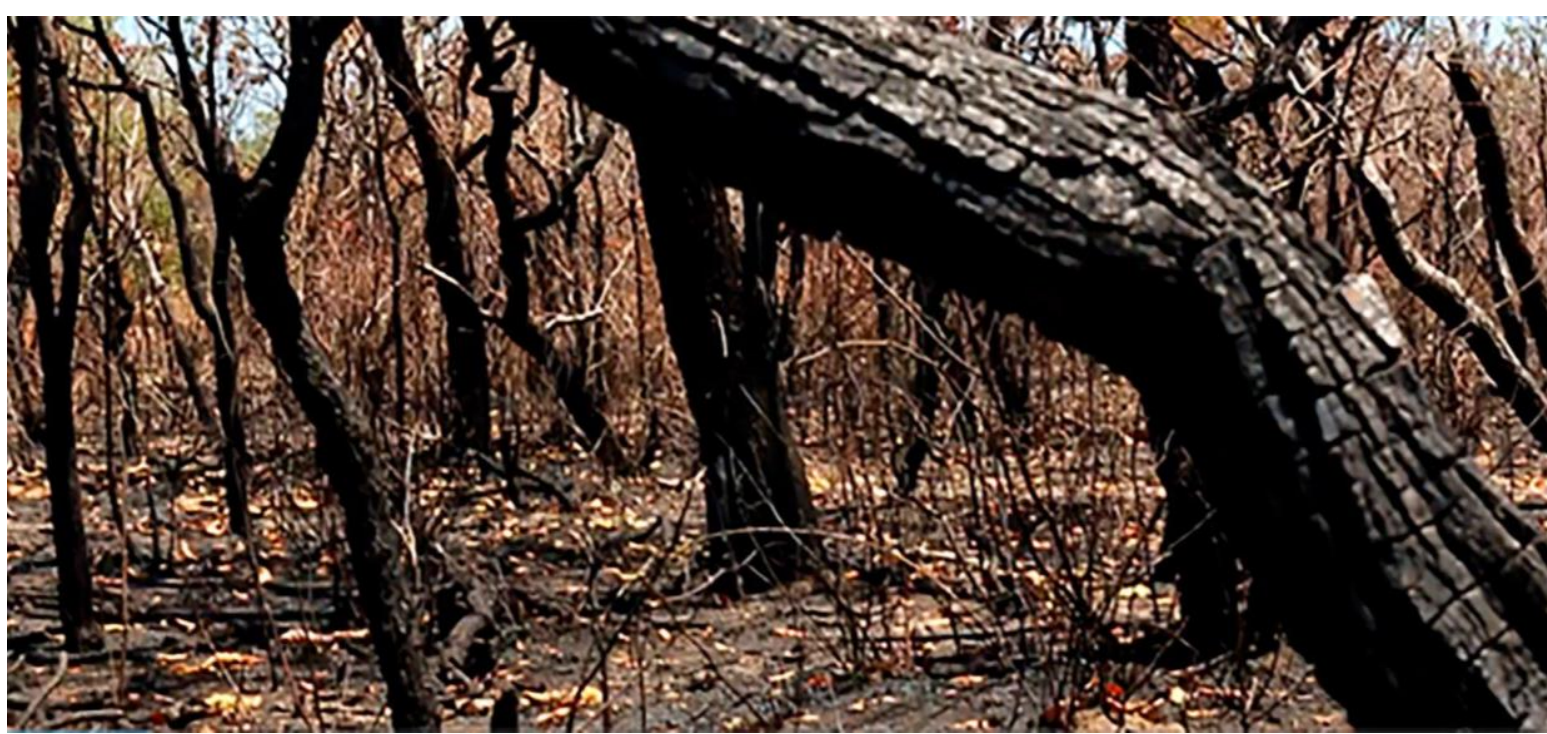

Imagem 2 - As sombras da degradação

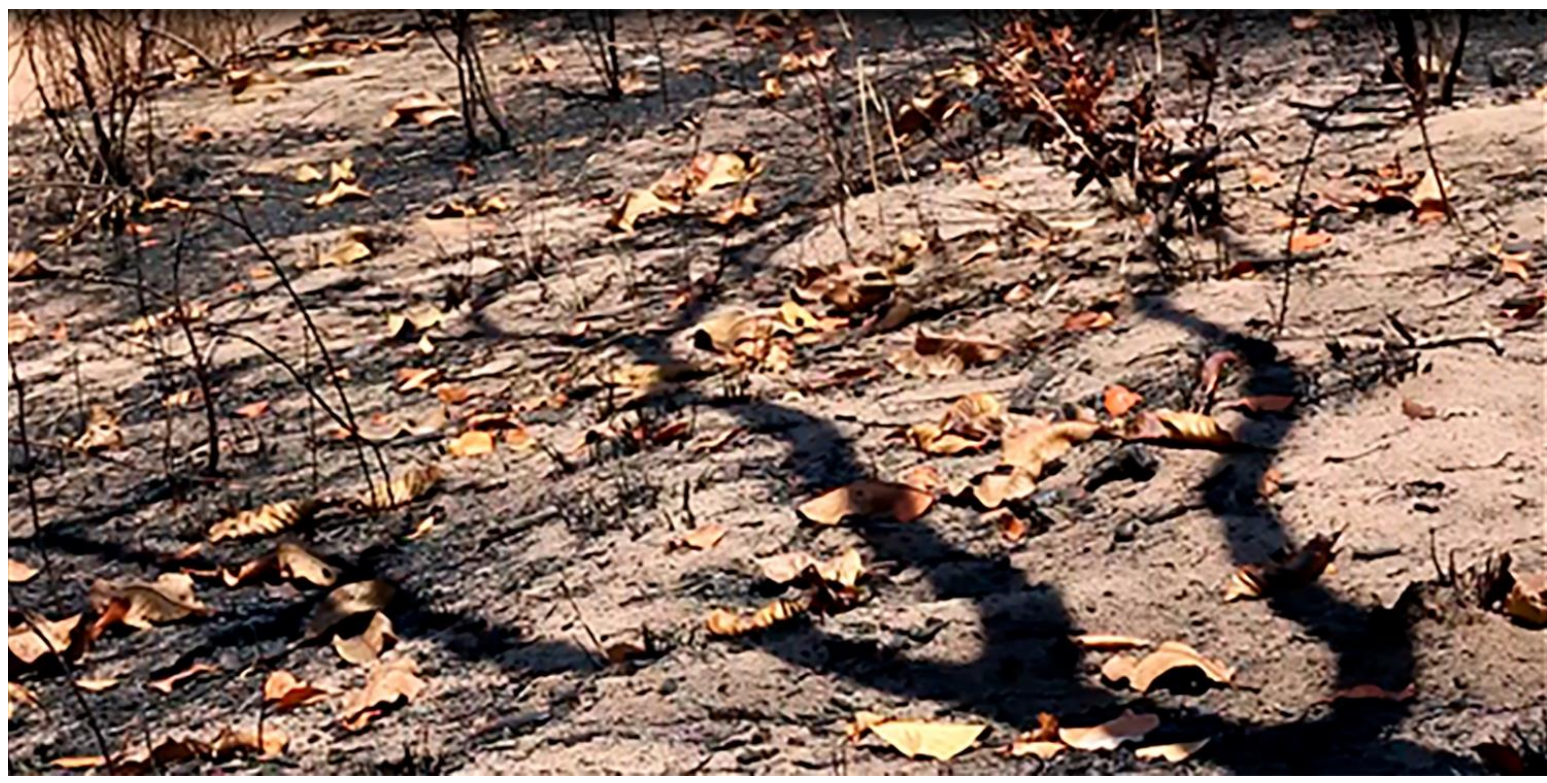


Imagem 3 - A flora é resiliente?

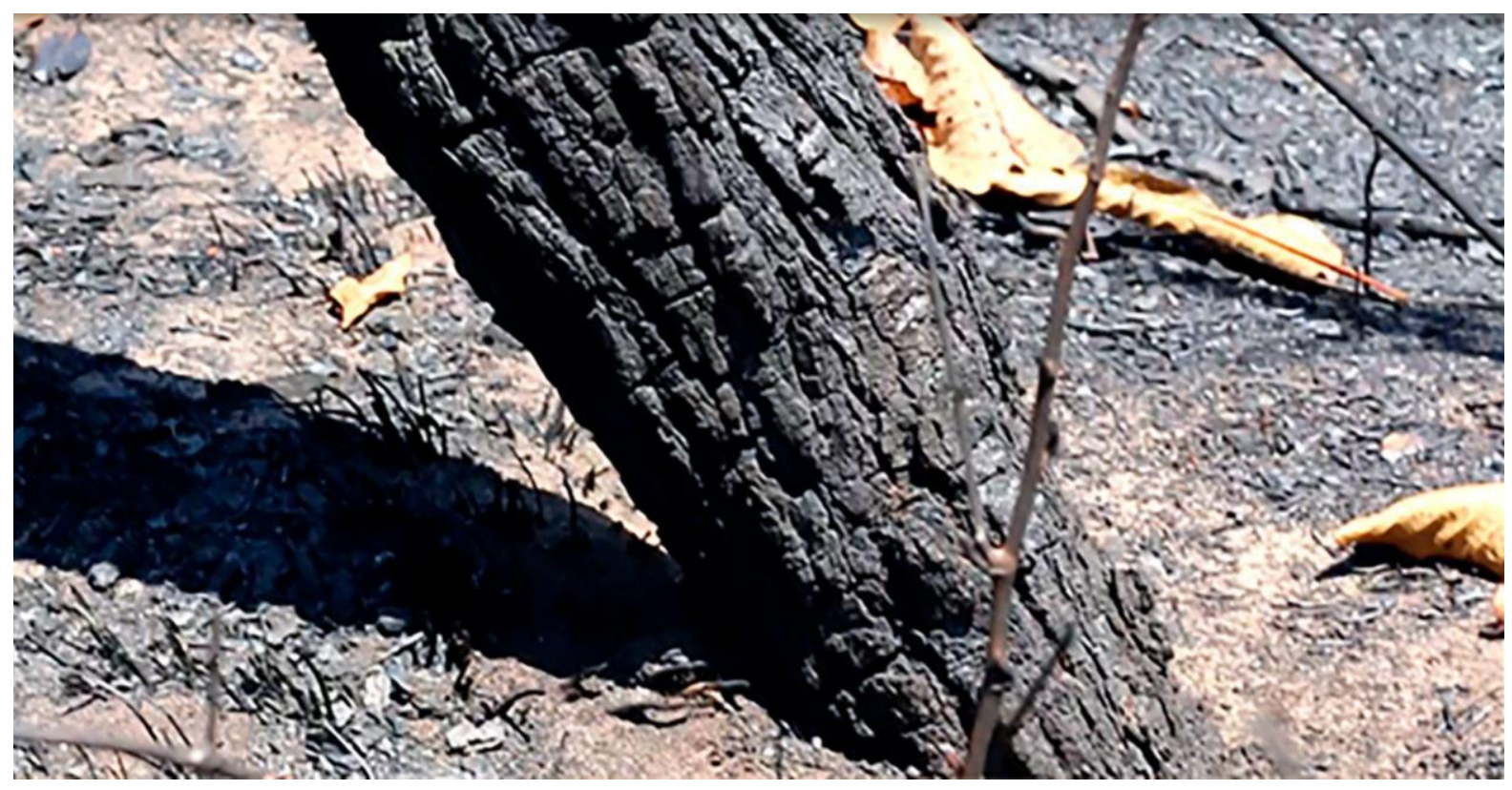


Imagem 4 - A fauna que não sobreviveu

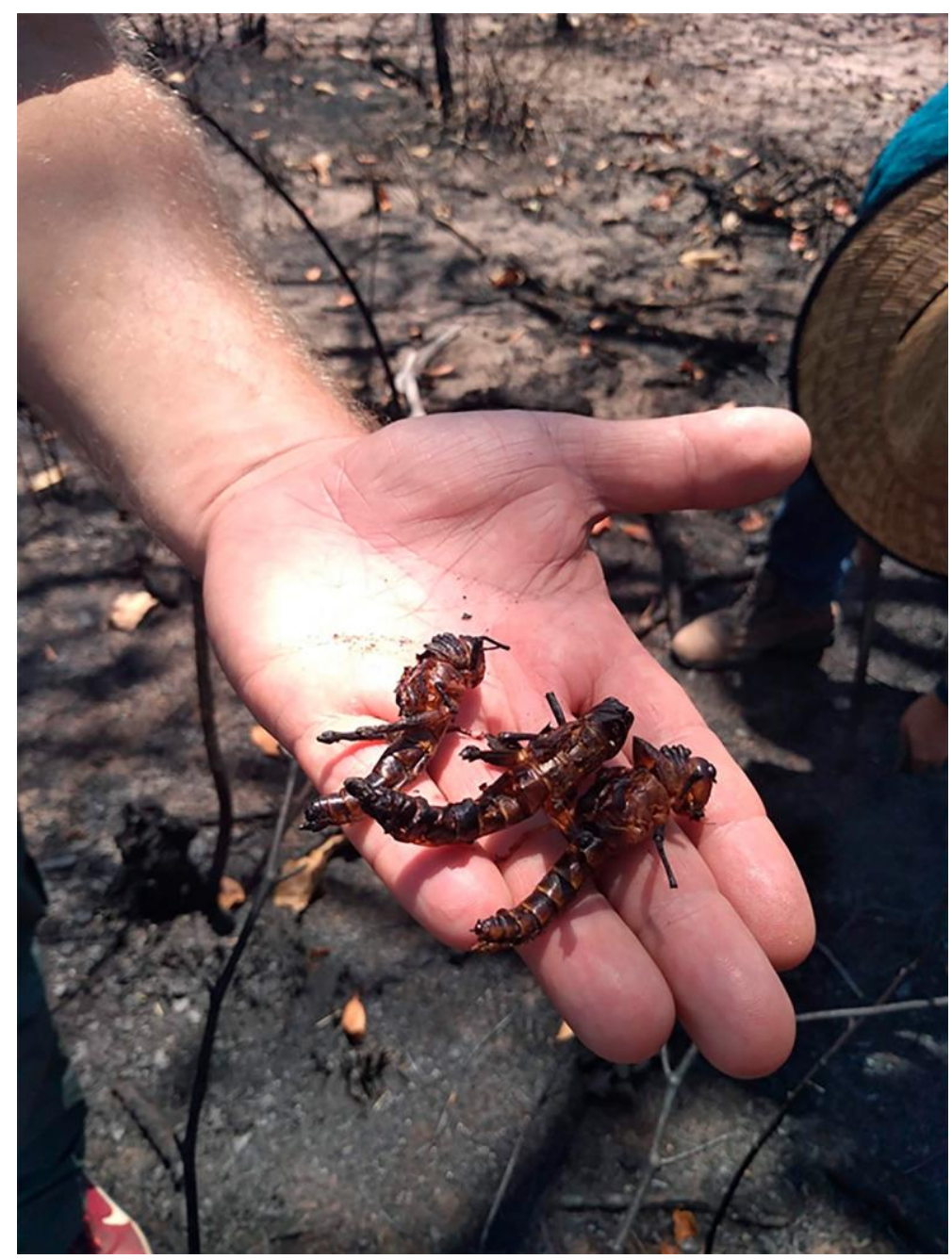


Imagem 5 - Os efeitos do desastre no solo

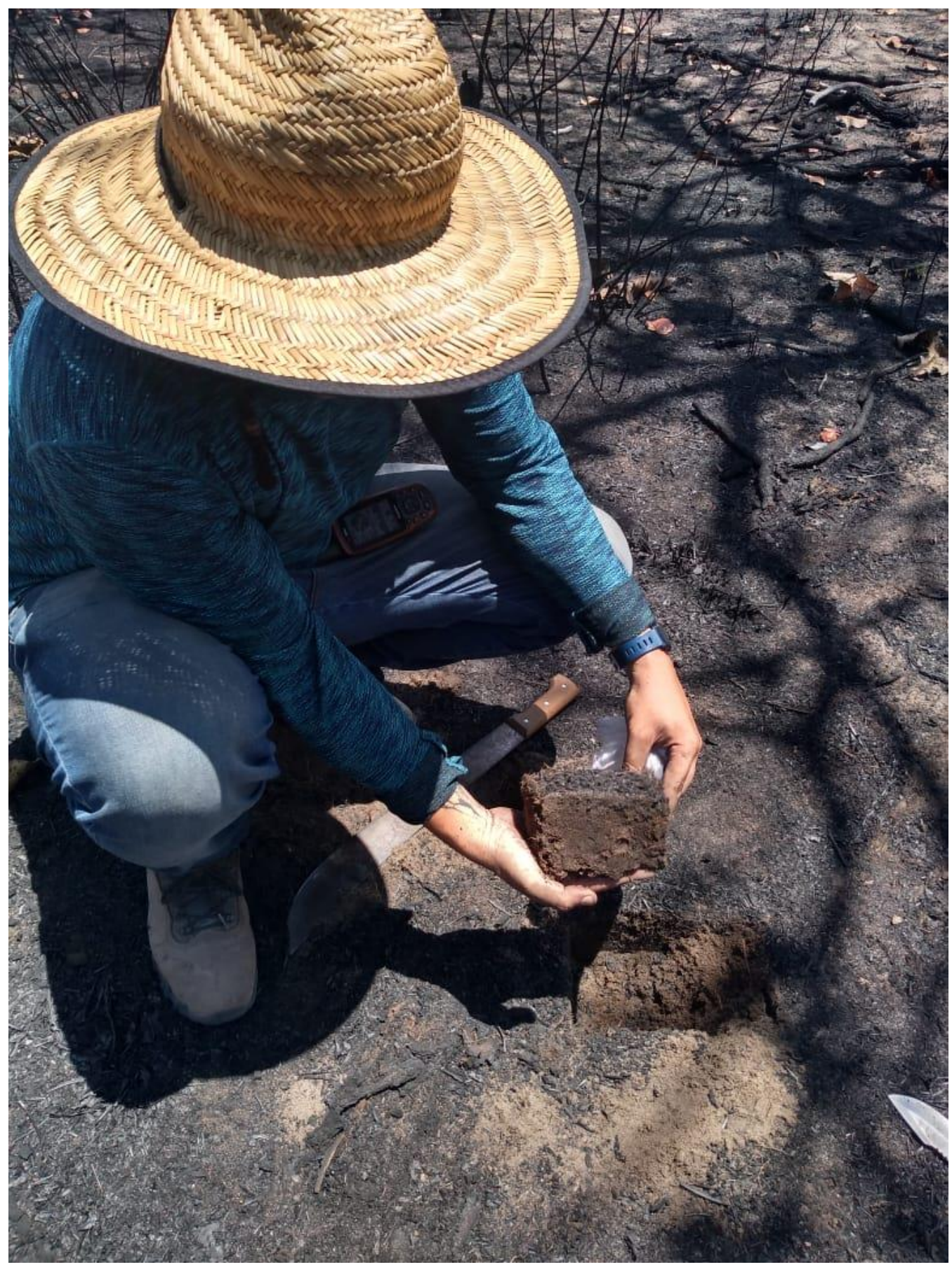


Imagem 6 - Os brigadistas, os pesquisadores, a savana queimada e o fragmento de floresta

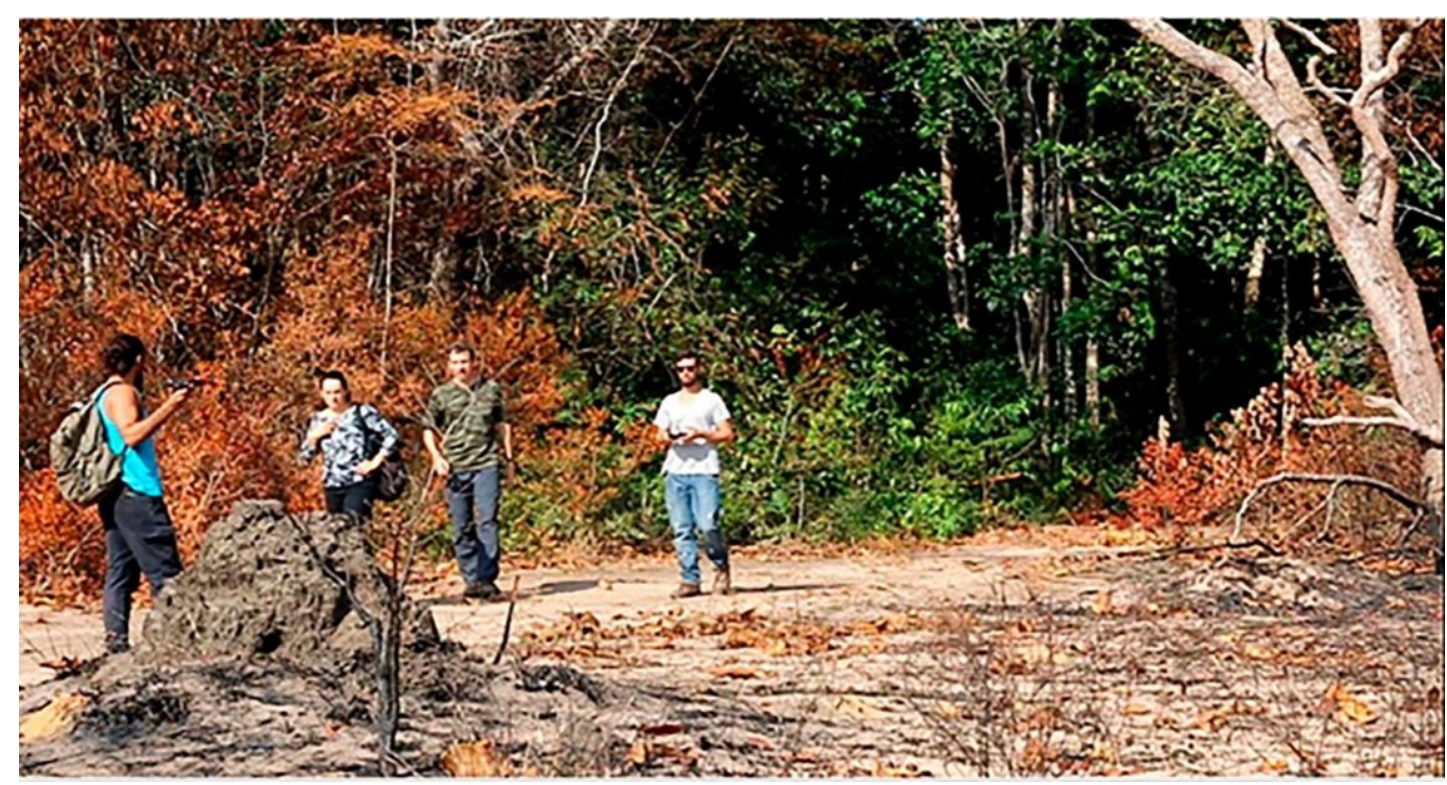


Imagem 7 - A vida florescendo depois do incêndio

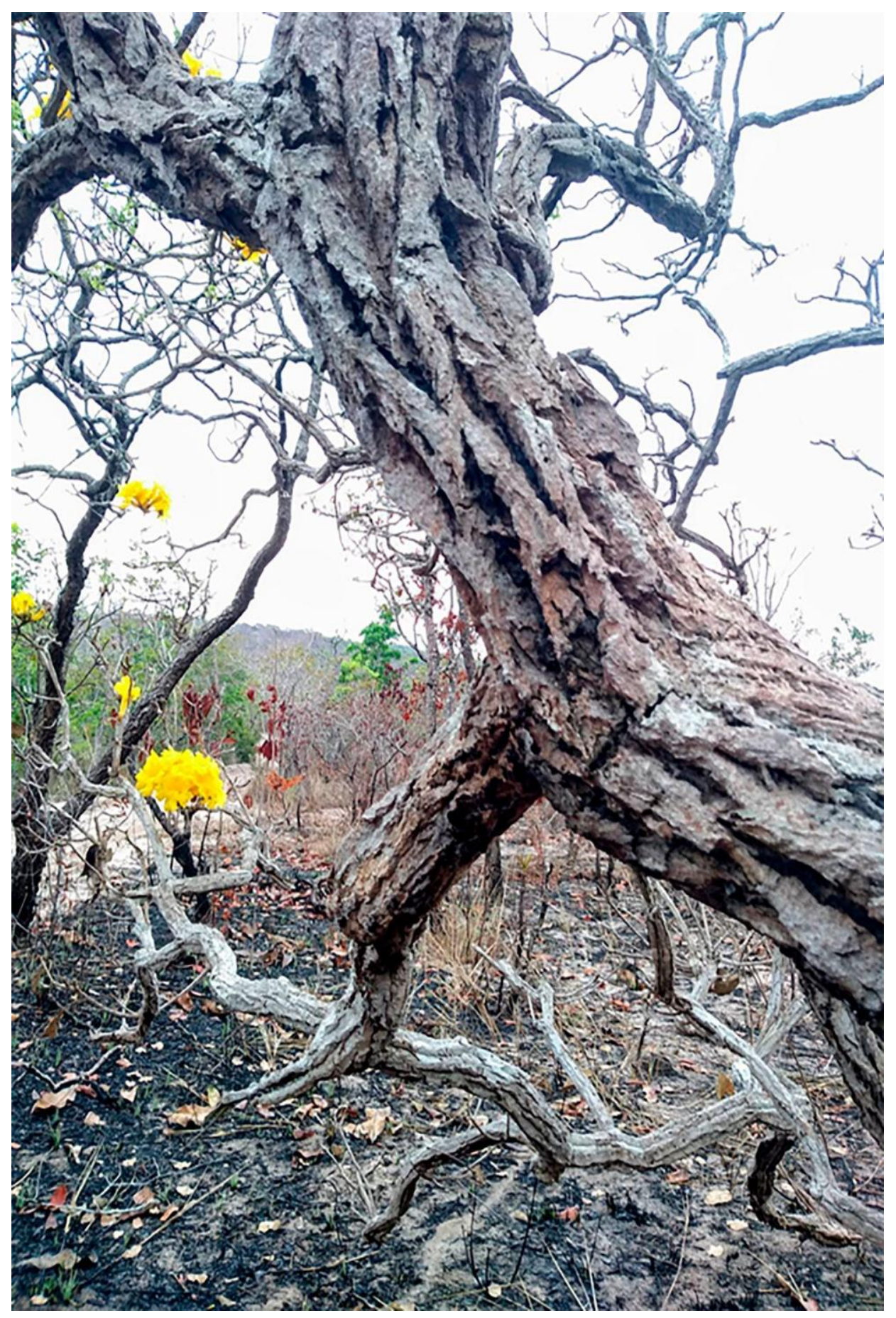


Imagem 7 - A fuga das abelhas e a composição híbrida da rede da savana por causa do fogo

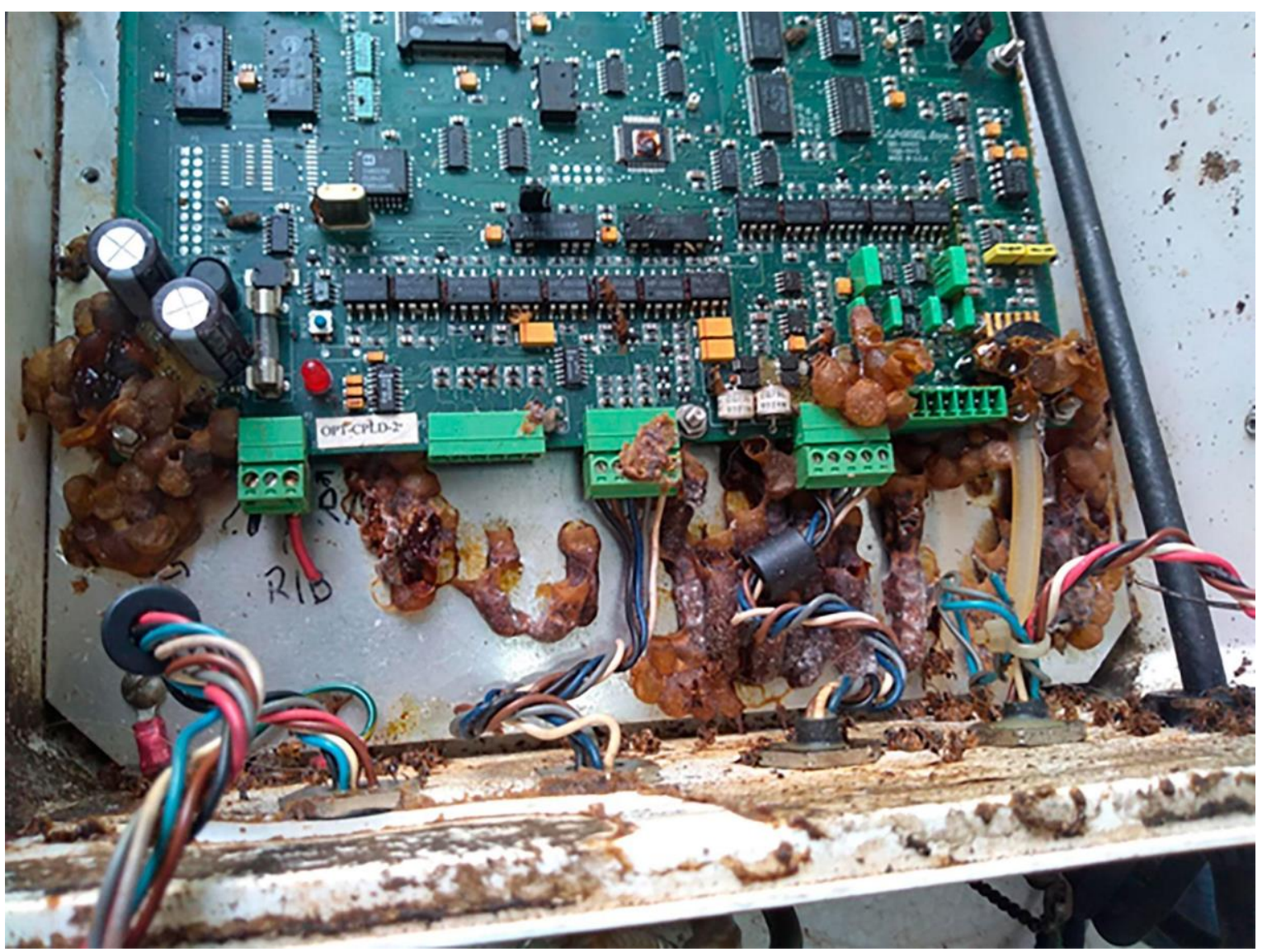


Imagem 8 - O coletivo no laboratório separando o inseparável: a sociedade, o objeto técnico e a natureza.

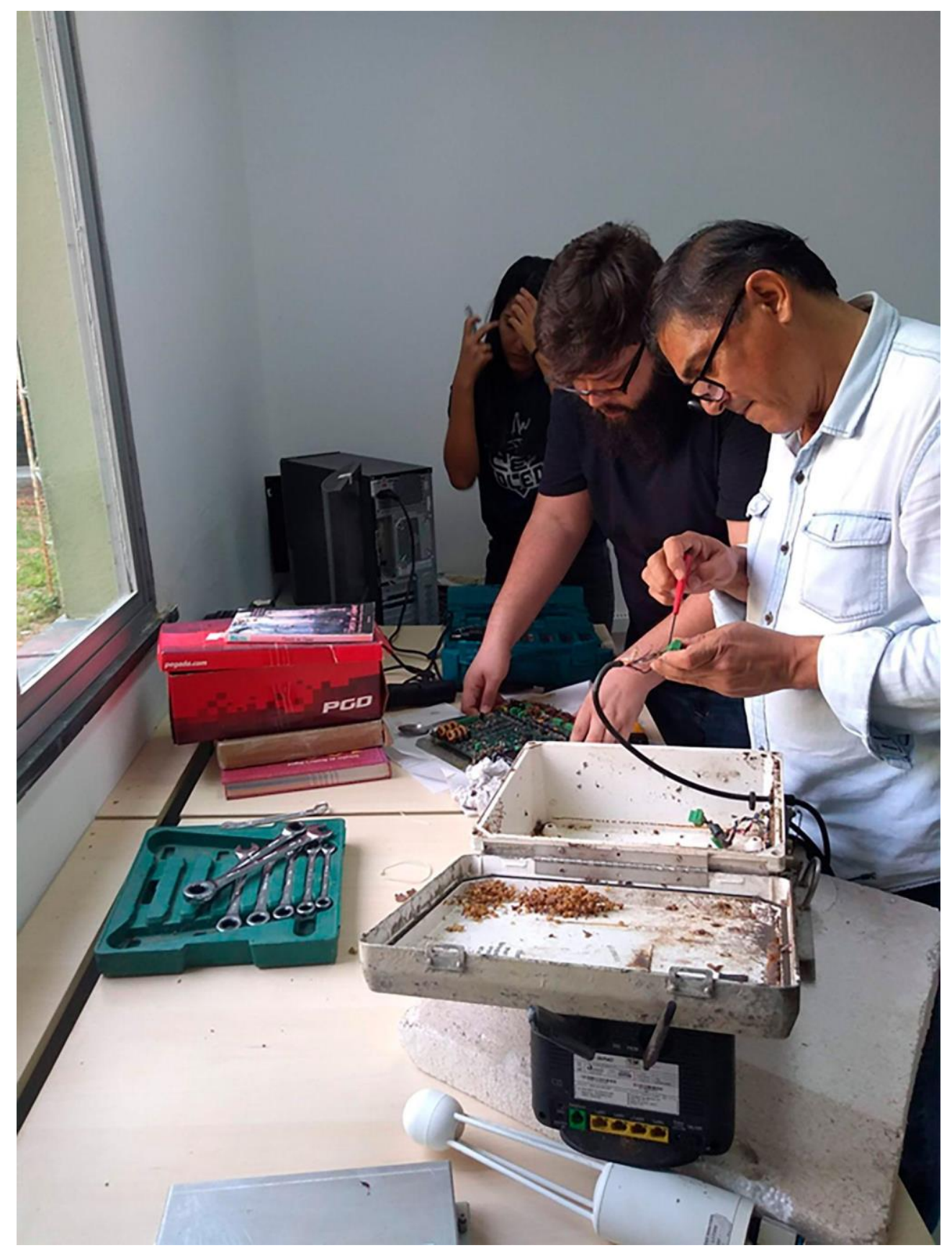




\section{Referências}

BARROS, Laura Pozzana; KASTRUP, Vírginia. Cartografar é acompanhar processos. In: PASSOS, Eduardo; KASTRUP, Virgínia; ESCÓSIA, Liliana. Pistas do Método da cartografia: pesquisa-intervenção e produção de subjetividade. Porto Alegre: Editora Sulina, 2015 .

CLIFFORD, James. A experiência etnográfica: antropologia e literatura no século XX. Rio de Janeiro: Editora da UFRJ: 2014.

LATOUR, Bruno; WOOLGAR, Steve. 1997. A vida de laboratório: a produção dos fatos científicos. Rio de Janeiro: Relume Dumará, 1988.

Jamais Fomos Modernos: ensaio de Antropologia Simétrica. Rio de Janeiro: Ed. 34, 1994.

Reagregando o Social. Bauru, SP: EDUSC/ Salvador, BA:EDUFBA, 2012.

Data de submissão: 01 de setembro de 2021

Data de publicação: 20 de dezembro de 2021 